\section{Um antropólogo sem qualidades}

LIMA, Nísia Trindade e SÁ, Dominich Miranda de (orgs.). Antropologia brasiliana: ciência e educação na obra de Edgard Roquette-Pinto. Belo Horizonte/Rio de Janeiro, Editora da UFMG/Editora Fiocruz, 2008, 327 páginas.

\section{André Botelho}

Brasiliana é um desses termos que parecem mesmo destinados a fazer fortuna no pensamento brasileiro. Desde sua "invenção", salvo engano, por Manuel de Araújo Porto-alegre no título da coletânea de suas poesias líricas, publicada em Viena em 1863, até sua consagração no título de uma das mais prestigiosas coleções de "assuntos brasileiros" editadas no país, $A$ Brasiliana, criada em 1931 sob a direção de Fernando de Azevedo. Brasiliana foi também o termo escolhido para qualificar a antropologia de Roquette-Pinto no título da coletânea organizada por Nísia Trindade Lima e Dominichi Miranda de Sá: Antropologia brasiliana: ciência e educação na obra de Edgard Roquette-Pinto. Ensaios brasilianos foi, aliás, o título adotado pelo próprio Roquette-Pinto para sua coletânea, publicada em 1941, dos perfis daqueles que, a seu ver, haviam contribuído para o desenvolvimento da ciência no Brasil. Ainda que não se trate de pressupor alguma estabilidade semântica para o termo ao longo do tempo, chama a atenção o significado perene de "coleção" de manifestações "brasileiras" que brasiliana encerra.

O objeto principal deste Antropologia brasiliana é a surpreendentemente multifacetada, rica e desafiadora trajetória intelectual de Edgar Roquette-Pinto. Comumente lembrado, até então, muito mais por suas ações pioneiras na área da comunicação, Roquette-Pinto emerge do livro como uma personagem múltipla num retrato integrado - ainda que cubista, como bem observou Robert Wegner no prefácio ao livro. Foram mesmo notáveis as suas realizações no rádio e no cinema educativos, a começar pela criação, por sua iniciativa, da Rádio Sociedade (atual Rádio MEC) pela Academia Brasileira de Ciências, em 1923; a criação da Seção de Museus e Radiodifusão da Secretaria de Educação e Cultura do então
Distrito Federal, em 1934, na criação da Rádio Escola Municipal (posteriormente denominada Rádio Roquette-Pinto) e na criação do Instituto Nacional de Censura Cinematográfica (INCE), em 1936. Realizações que lhe asseguram ainda hoje um merecido lugar de destaque na história da divulgação científica no país. Mas a trajetória intelectual de Roquette-Pinto, como agora podemos saber, é bem mais ampla, diversificada e complexa. Médico por formação, tendo exercido atividades na área de medicina legal e sanitária, seu interesse pela antropologia física foi, contudo, aí despertado, bem como a, por assim dizer, sensibilidade etnográfica que lhe distingue - expressa já em sua tese, defendida em 1905, sobre a prática da medicina entre os índios. Professor do Museu Nacional do Rio de Janeiro por trinta anos desde 1905, foi também seu diretor entre 1926 e 1935. Membro da Academia Brasileira de Ciências e também um viajante, integrou, entre outras, expedições científicas ao Rio Grande do Sul, em 1906, e, em 1912, a Comissão de Linhas Telegráficas e Estratégicas de Mato Grosso ao Amazonas - a célebre Comissão Rondon. Ali, se ocupou especialmente em registrar as condições dos Nhambikuára e dos Paresís, apresentadas posteriormente no seu livro Rondônia, de 1917. Signatário do Manifesto dos Pioneiros da Educação Nova, de 1932, e partícipe da Liga Pró-saneamento do Brasil, que empreendeu a campanha para criação do Ministério da Saúde, Roquette-Pinto entendia que o analfabetismo e as doenças que grassavam sobre o território nacional, e não a composição racial da sua população, constituíam os verdadeiros problemas do Brasil e obstáculos ao exercício da cidadania democrática. Militante do Partido Socialista Brasileiro, pelo qual chegou a se candidatar à Câmara Federal em 1954, foi, como grande parte da sua geração, intelectualmente muito marcado pelo positivismo. Positivismo esse confesso, ainda que heterodoxo, que o fez membro da Associação Brasileira dos Amigos de Augusto Comte. Como não poderia deixar de ser, Roquette-Pinto também deixou alguns projetos que não lograram sair do papel: dicionários de medicina, uma revista de divulgação científica voltada para operários, um museu da técnica, a tradução de relatos de naturalistas alemães que visitaram o Brasil no século XVIII e até 
mesmo uma proposta de reformulação da bandeira nacional, entre outros. Enfim, uma trajetória intelectual que encerra em si mesma uma verdadeira brasiliana.

Antropologia brasiliana: ciência e educação na obra de Edgard Roquette-Pinto é composto por quatro partes. A primeira delas é aberta por um ensaio do próprio Roquette-Pinto, "Ciência e cientistas do Brasil", encontrado em seu acervo pessoal na Academia Brasileira de Letras. Seguem-se, ainda nesta parte, os comentários de Dominichi Miranda de Sá ao referido ensaio, além de um dos textos-chave da coletânea, "Roquette-Pinto e sua geração na república das letras e da ciência", de autoria das organizadoras do livro. "Positivismo e nação", a segunda parte, compreende estudos que rediscutem, sempre a partir do antropólogo carioca, as relações entre ciência e sociedade em geral, e o papel da antropologia da época, em particular, sobretudo, nos projetos de integração territorial e de modernização da sociedade brasileira. A antropologia volta à cena na terceira parte, particularmente para evidenciar o lugar de Roquette-Pinto no debate sobe a questão racial do seu tempo e sua posição crítica em relação à tese, então hegemônica, da degeneração decorrente da mestiçagem, especialmente em relação aos sertanejos que ele pôde conhecer de perto nas expedições cientificas das quais participou. Na última parte, "Ciência e ação", são analisadas as experiências pioneiras de Roquette-Pinto no emprego das então novas tecnologias audiovisuais como recursos cruciais tanto para a divulgação científica, quanto para a realização de etnografias e para o ofício do antropólogo como um todo.

Antropologia brasiliana pode ser, num certo sentido, considerado como parte de um conjunto mais amplo de pesquisas desenvolvidas nas últimas décadas na Casa de Oswaldo Cruz (Fiocruz) sobre as representações da vida social formuladas em discursos e teorias científicas. E isso não apenas em função da filiação institucional das organizadoras do livro, mas sobretudo pelo fato da agenda de pesquisa que encerra ser inteiramente convergente aos interesses mais amplos das pesquisas desenvolvidas naquela instituição. Nessas, vêm ganhando novos sentidos sociológicos e historiográficos materiais como os relatórios produzidos nas viagens científicas de conhecimento do território, dos recursos naturais e das populações dos interiores; as idéias e as políticas públicas de saúde; as idéias científicas que tiveram papel acentuado na construção de imagens sobre as populações rurais, entre outros. Materiais que vêm sendo tratados não como peças técnicas produzidas por especialistas, mas sim como interpretações do Brasil que, a exemplo dos ensaios clássicos dos anos 1930 ou da produção acadêmica das ciências sociais da década de 1950, proporcionam não apenas significados à vida social brasileira como também sentido às ações e aos processos que, conflituosamente, a tem constituído. Se essa interação entre as agendas de pesquisa da história das ciências e do pensamento social brasileiro tem proporcionado que novas problemáticas ganhem atenção na primeira área de pesquisa, vem operando igualmente um alargamento cognitivo da própria noção de pensamento social e da história das ciências sociais no Brasil. Não por acaso, portanto, essas áreas de pesquisa se encontram e se influenciam mutuamente também neste Antropologia brasiliana - interação que, neste caso, é particularmente exigida pelo próprio caráter múltiplo das atividades e dos domínios do conhecimento compreendidos na trajetória de Roquette-Pinto.

Como todo livro, também Antropologia brasiliana tem sua própria história. A que nos é dada a conhecer na apresentação da obra talvez nos ajude a compreendê-lo melhor. Segundo suas organizadoras, o livro remonta à pesquisa por elas realizada no acervo da Academia Brasileira de Letras (ABL) em 2001, o que as teria permitido, em 2004, quando se comemorou o cinqüentenário de falecimento de Roquette-Pinto, "estimular o debate acadêmico em torno da contribuição da obra do homenageado" (p. 17) numa série de atividades, como o seminário "Ensaios brasilianos" e a exposição "Roquette-Pinto: um brasiliano". Os artigos reunidos no livro foram, em grande parte, como informam as organizadoras, originalmente apresentados e discutidos nesses dois eventos. Perceba o leitor, então, que a idéia de "brasiliana" já permeava as atividades que originaram o livro, mas a novidade deste parece estar codificada na passagem de "ensaio", como figura no título do seminário e da exposição (ou mesmo do próprio antropólogo individualmente considerado), para a 
"antropologia", como aparece no título do livro agora publicado. Assim sendo, podemos então especular se a antropologia não representa de alguma forma um elemento unificador dessa "coleção" de manifestações brasileiras, ou seja, das múltiplas realizações de Roquette-Pinto.

É certo que tentativas de aproximação a qualquer sentido unificador são ainda mais difíceis, senão problemáticas, em relação a coletâneas, dada a inevitável diversidade de posições que a caracterizam. Tal como nos retratos cubistas, para desdobrar a metáfora de Robert Wegner sobre o livro, não se trata de sugerir representações intencionais, mas composições resultantes da sobreposição de traços que fazem do retrato um motivo para o exercício de especulação plástico-narrativa. Assim, é tentador ao menos destacar analiticamente um desses traços sobrepostos que, embora presente em medidas diferentes nos capítulos que o compõem, dão força ao conjunto deste Antropologia brasiliana. Trata-se da valorização das práticas cotidianas dos cientistas, nas múltiplas direções que então encerravam, mas contextualizadas em sua sociedade e em seu tempo, como a matéria mesma de uma história da ciência, aqui flagrada em toda a complexidade e riqueza de uma disciplina - a antropologia - em seu momento de sistematização interna e em relação a outros domínios do conhecimento.

Ao reconstituir as múltiplas ações profissionais (e mesmo as amadoras) do antropólogo carioca na vida intelectual brasileira da primeira metade do século XX, o livro oferece também elementos cruciais que estimulam rever e rediscutir a história das ciências sociais no Brasil. Fundamental para tanto é a adoção, na leitura, de uma perspectiva mais ampla do que a institucional usualmente empregada na construção da inteligibilidade sociológica desse processo, uma perspectiva voltada antes para as práticas cotidianas do cientista do que para o sentido normativo que algumas delas acabariam por assumir posteriormente. Perspectiva que, sem excluir a dimensão institucional da vida científica, problematiza a premissa da sua autonomia, como se as instituições fossem em si mesmas capazes de transformar estritamente, segundo sua lógica própria, a dinâmica social ou a conduta e a subjetividade individuais. Por isso não aparecem no livro divisões estanques entre produção pré-científica e científica; as instituições não figuram como refúgios para especialistas, mas antes como espaços de mediação e comunicação entre o cientista/intelectual e a sociedade; e mesmo o compromisso com o desenvolvimento social, com a democratização e com a emancipação dos indivíduos que, como homem de seu tempo, Roquette-Pinto entendia ser constitutivo da prática científica, não pareça poder ser descartado como um fenômeno secundário.

Daí o sentido mais próximo desse Antropologia brasiliana: uma recomposição entre sujeito e objeto, entre o indivíduo, sua subjetividade e as objetivações que oferece, num plano mais vasto, elementos para uma visão renovada da história das ciências sociais. Isso porque, em primeiro lugar, não a submete a simplificações demasiado ordeiras e, em segundo, dado o caráter múltiplo das atividades de Roquette-Pinto, a antropologia e as ciências sociais são vistas em interação com outros domínios e práticas do conhecimento. Então, de Edgard Roquette-Pinto talvez se possa dizer, em suma, o mesmo que o narrador de $O$ homem sem qualidades, o romance inacabado de Robert Musil, diz de Ulrich, seu protagonista: "Era menos um cientista do que alguém humanamente apaixonado pela ciência" (Musil, 1989, p. 31). Mas isso desde que não se minimize a ironia crucial envolvida na dificuldade de Ulrich em tornar-se um "especialista rigoroso", pela sua incapacidade de colocar-se "antolhos" - uma das condições, como advertia Max Weber (1982), para a realização da moderna ciência. Afinal, aquela dificuldade aparece como expressão mesma de que as "qualidades" que lhe faltavam correspondiam ao próprio alheamento do cientista do processo social mais amplo em que se insere! Não resta dúvida de que as práticas cotidianas do multifacetado RoquettePinto são próprias do momento histórico da sociedade brasileira e das ciências do seu tempo. Isso não significa, porém, que o sentido dessas práticas e dos valores a elas associados tendam necessariamente a se esgotar em sua própria individualidade histórica, como se nada mais tivessem a nos dizer hoje. Que o leitor se deixe interpelar pelo livro, é o meu convite. 


\section{BIBLIOGRAFIA}

MUSIL, R. (1989), O homem sem qualidades. Rio de Janeiro, Nova Fronteira.

WEBER, M. (1982), "A ciência como vocação", in Ensaios de sociologia, Rio de Janeiro, Guanabara, pp. 154-183.

ANDRÉ BOTELHO é professor do Programa de Pós-Graduação e Antropologia (PPGSA/IFCS/UFRJ) e pesquisador do CNPq.

E-mail: andrebotelho@digirotas.com.br 